\title{
O Papel da (nano) ciência e da (nano) tecnologia nas políticas agrícolas brasileiras: revisitando argumentos históricos
}

Jorge Luiz dos Santos Junior ${ }^{1}$

Wander Luiz Pereira dos Santos ${ }^{2}$

\section{Resumo}

Este artigo tem como objetivo discutir o desenvolvimento científico e tecnológico brasileiro a partir da formulação das políticas públicas, em especial aquelas voltadas para a agricultura. Para tanto, faz-se uma incursão sobre o papel desempenhado pela agricultura no processo de desenvolvimento nacional, ao apresentar funções específicas e pré-determinadas dentro da lógica da industrialização e da tecnologia autóctone. A partir de uma perspectiva crítica, o artigo avança no sentido de mostrar as transformações no setor agrícola com a introdução de nanotecnologias, revelando como este processo se desloca de uma perspectiva de desenvolvimento sustentável, na medida em que fortalece, mais uma vez, a indústria do agronegócio e penaliza a agricultura familiar. Ao desvelar os equívocos dessas políticas, propõem-se novos caminhos a serem perseguidos pelo Estado no encalço de um desenvolvimento social mais justo e solidário. Palavras-Chave: Nanoagricultura, Nanofoods, Política de Estado, Agricultura familiar.

1 Doutor em Ciência Sociais em Desenvolvimento, Agricultura e Sociedade. Professor do Departamento de Engenharia de Produção da Universidade Federal do Espírito Santo. E-mail: jjuniorsan@yahoo.com.br

2 Cientista Social (UFES) e Mestre em Cognição e Linguagem (UENF), Professor do Instituto Federal de Educação, Ciência e Tecnologia do Espírito Santo (Campus Vitória). E-mail: wandersan@yahoo.com.br 


\section{The Role of (nano)science and (nano) technology in Brazilian agricultural policies: revisiting historical arguments}

\section{Abstract}

This paper aims to discuss the Brazilian scientific and technological development since public policies set up focusing on those related to agriculture. Therefore, we analyze the role played by agriculture in the Brazilian development process by providing specific and pre-determined function within the both industrialization logic and called autochthonous technology. On a critical perspective, the article shows the changes in the agriculture that came from the wider use of nanotechnologies, revealing how this process moves from a sustainable development perspective due it re-strengthens agribusiness as well penalizes family farming. Revealing the mistakes of these policies, the paper proposes new approaches to be pursued by the State in order to reach a fairy and more solidary social development.

Keywords: Nanoagriculture, Nanofoods, Public Policy, Family Farming.

\section{I - Introdução}

No período compreendido entre o final da década de 1990 e início dos anos 2000 o mundo presenciou a consolidação e ampliação dos estudos sobre as tecnologias atômicas, apoiando-se nas oportunidades abertas pelas novas tecnologias de informação, sobretudo aquelas que ampliaram a capacidade de processamento de imagens e manipulação dos átomos. Nesse processo, o aspecto essencial está na viabilidade de se manipular adequadamente átomos e moléculas de elementos vivos e não-vivos, onde 
se desenvolvem novos produtos e processos com várias possibilidades de aplicação; da indústria aeronáutica à agricultura, da mecatrônica à nanobiotecnologia molecular. Essas atividades se consubstanciaram em pesquisas na área de Nanociência e Nanotecnologia $(\mathrm{N} \& \mathrm{~N})$.

Um pouco antes, ou talvez concomitante a esse processo, na agricultura $^{3}$, a qual os estudos se transformam rapidamente em produtos e patentes, os avanços em biotecnologia foram responsáveis pelo desenvolvimento de novas formas de lidar com predadores e aumentaram o estado da arte do conhecimento sobre a vida. Além disso, criaram-se organismos geneticamente modificados (OGMs), fomentando a discussão em torno do papel social do desenvolvimento tecnológico, sobretudo quando da introdução das sementes transgênicas.

A partir das iniciativas em $\mathrm{N} \& \mathrm{~N}$ as possibilidades evoluíram para além das sementes e penetraram em toda a estrutura produtiva (da produção de sementes, passando pelas técnicas de plantio, fertilização do solo e colheita - a nanoagricultura; da commodity ao produto nanoprocessado - os nanoalimentos). Convergindo com outras tecnologias (Tecnologias da Informação, Biotecnologias e Ciências Cognitivas) emerge as várias e novas possibilidades para toda a cadeia produtiva da agricultura.

É sempre conveniente lembrar que a novidade em relação às outras tecnologias revolucionárias surge porque com as N\&Ns a perspectiva da produção Top down (a miniaturização, como um artesão esculpindo sua obra) fica invertida. Seguindo o caminho inverso, de baixo para cima, a construção de tecnologias a partir de sua menor estrutura, a tecnologia Botton Up (Zubarev, rural, inclusive a pecuária, produção de peixes, entre outras. 
2013; Santos Junior, 2013; Regis, 1997), abre-se caminho para projetos de impacto inovativo incomensurável. A perspectiva da destruição criativa (Schumpeter, 1982) avança para o desenvolvimento não somente do novo a partir dos insumos existentes, mas também do desenvolvimento de novas substâncias capazes de modificar completamente a natureza da matéria.

Com a manipulação de átomos individualmente os cientistas vislumbraram as possibilidades de se usar nanotecnologias em todos os campos científicos (física, química, biologia, etc.) e em suas diversas áreas (medicina, cosméticos, alimentos, novos materiais, energia, agricultura, etc.), o que aponta para um novo processo de destruição criativa bastante intenso (Santos Junior, 2013). Nesse processo, torna-se cada vez mais difícil isolar os impactos nos diversos setores de atividade, já que o que se desenvolve na indústria vai para a agricultura, sendo esta última transformada, tornando-se uma função da primeira.

Assim como ocorreu no caso da cadeia de produtos transgênicos, as nanotecnologias aplicadas à agricultura já são controladas por grandes empresas transnacionais, que patenteiam suas inovações e não raramente são utilizadas em conjunto no desenvolvimento de um novo produto. Essas tecnologias interferem diretamente no ciclo de vida dos seres, sendo assim, geram amplas oportunidades de utilização, mas também podem trazer riscos impensados para a sociedade.

Pelas razões elencadas e pelo que já se observa em termos de desenvolvimento de nanotecnologias aplicadas à agricultura e aos alimentos ao redor do mundo, é possível perceber que a revolução científica presente nas atividades de N\&N têm sido muito mais profunda do que a ascensão dos fertilizantes, corretivos e dos OGMs (Chen; Yada, 2011). Existe a previsão de ocorrência de alto impacto econômico e social, que requererá ampla transformação institucional, com novas regulamentações e acordos de comercialização e pesquisa. 
Assim, neste artigo, parte-se do pressuposto de que as nanotecnologias contribuem para alterar o padrão econômico da produção, principalmente agrícola, e também promovem alterações estruturais nas formas de participação dos atores sociais. Para acompanhar os investimentos necessários são requeridos volumes de capital incompatíveis com organizações produtivas menores, excluindo a produção de pequena escala, caso não existam mecanismos adequados de financiamento. Além disso, por se tratar de uma área de fronteira da ciência, as N\&Ns residem em um vasto oceano de incertezas e riscos potenciais.

Atualmente, não é possível perceber o desenvolvimento de uma nanotecnologia para a pequena produção, o que existe é uma indústria de nanotecnologia para a agricultura e que está concentrada nas mãos de oligopólios. 0 desenvolvimento recente das nanotecnologias tem sido incompatível com o padrão de produção da agricultura familiar no Brasil. Além disso, no Brasil, a análise de risco de nanomateriais no setor de alimentos e na agricultura não tem sido objeto direto de estudo por parte das pesquisas realizadas.

Diante desse cenário, busca-se entender as possibilidades de atuação do Estado brasileiro em relação a todo esse imbróglio, haja vista que em alguns países o tema já é pauta das políticas públicas, inclusive discutindo-se a questão da rotulagem. Para tanto, a seção II traz uma incursão histórica sobre o papel desempenhado pela agricultura como fomento ao avanço industrial brasileiro na segunda metade do século XX, uma revolução verde à brasileira. A seção III explica o estágio de desenvolvimento das N\&Ns aplicadas à agricultura ao redor do mundo; processo caracterizado como Revolução Incolor. Já a seção IV tem a função de apresentar ao leitor as inconsistências das iniciativas em N\&N no Brasil, revelando o seu alto poder concentrador. Na quinta seção são rascunhadas algumas possibilidades para as políticas públicas brasileiras. Por fim, na sexta seção são tecidas algumas considerações finais. 


\section{Revolução verde à brasileira: a agricultura e a orientação das políticas de desenvolvimento ${ }^{4}$}

No Brasil, debates em torno da agricultura nos anos 1960 caracterizaram-na como o ponto de estrangulamento das atividades produtivas do país. A grande questão que pairava na mente dos governantes e de alguns intelectuais era: como garantir o suprimento de alimentos, cuja demanda crescia exponencialmente; sobretudo pela intensificação das atividades industriais na cidade; sem comprometer o equilíbrio macroeconômico? Veja-se que se tratava de um estrangulamento relativo, na medida em que aparecia como um entrave aos anseios de um prospectado Brasil industrial.

A partir dessa problemática, ganhou legitimação a "interpretação funcionalista da agricultura". Delgado (2005) destaca que esse tipo de visão possui uma matriz "Uspiana" representada por figuras como Delfin Neto, que selecionou as seguintes funções para o setor: a) Liberação da mão-de-obra para a cidade sem reduzir produção; b) criação de mercado para os produtos da indústria; c) expansão das exportações e do financiamento de parte da capitalização da economia. Está evidente nessas colocações uma visão modernizadora.

Para os intelectuais que compactuavam com essa visão, o modelo agrícola brasileiro era visto à época como um entrave ao desenvolvimento nacional. De acordo com Gonçalves Neto (1997), esse tipo de interpretação apresentava os seguintes argumentos: a) sem modernização agrícola os preços subiriam, achatando e comprometendo os lucros no setor industrial; e b) formas arcaicas de produção não criavam mercado consumidor para a indústria e não criavam um setor forte de indústria para a agricultura.

4 Parte desta seção foi produzida nas reflexões presentes em Santos Junior e Chain (2009). 
Assim, no Brasil, a segunda metade do século XX foi caracterizada por mudanças profundas no cenário econômico, respaldadas por uma inversão na matriz produtiva nacional que deslocou o setor dinâmico da economia; da agricultura para a indústria. A modernização foi responsável pela transformação da base técnica da agricultura (uso intensivo de fertilizantes, defensivos, sementes, máquinas e implementos diversos), que possibilitou a industrialização deste setor, tendo como principal característica a internacionalização e integração de ramos da indústria e dos serviços ligados ao meio rural.

Destacando as funções da agricultura no desenvolvimento brasileiro e diagnosticando entraves existentes no setor, esse tipo de interpretação subsidiou a elaboração de políticas modernizantes sui generis, pois o processo ocorreria sem nenhuma reforma estrutural, ou seja, sem reforma agrária, sem mudança de classe dominante. Transformava-se a estrutura produtiva arcaica, mas não a estrutura agrária oligárquica (e também arcaica).

A introdução de novos métodos de produção e, sobretudo, a introdução de um setor voltado para o desenvolvimento de tecnologias mecânicas, foi determinante para o estabelecimento de um novo padrão de acumulação rural tributado pelo processo de industrialização, em que a agricultura aparece como um ramo da indústria e por ela transformada (Leite, 2005).

Nesse contexto, o Estado limitou-se a acionar incentivos fiscais e creditícios, orientado pela "modernização" a qualquer custo, o que fez com que não se alterasse o status quo da agricultura (Kageyama; Graziano da Silva, 1987). Dito de outra forma, apesar de toda modernização, o setor agrícola continuou com uma estrutura concentrada, sobretudo porque a modernização privilegiou aqueles mais aptos a estabelecer as parcerias necessárias para a obtenção de créditos (Gonçalves Neto, 1997).

O Estado, segundo Kageyama e Graziano da Silva, foi eficaz no que se refere à criação de uma política de crédito, promovendo 
o que estes autores chamam de "modernização compulsória", ou seja, o crédito estava atrelado às práticas agrícolas modernas. "Mais do que dizer como produzir, o Estado passou a manipular os instrumentos de política visando indicar o que e quando produzir" (Kageyama; Graziano da Silva, 1987, p. 168).

Isso explica o fato de que, diferentemente do que ocorreu para o setor industrial, o qual foi possível identificar um amplo processo de planejamento, não se elaborou para o setor agrícola programas específicos de intervenção e planejamento de longo prazo. Todas as ações, sobretudo creditícias, que se pode observar até a década de 1980, tiveram como objetivo promover o setor industrial, seja através do fortalecimento da indústria de insumos, seja pela internalização de D1 (indústria de máquinas). A agricultura ficava a reboque do crescimento industrial.

Outro ponto crítico aparece quando se identifica que não houve papel suficiente do Estado no sentido de controlar e fiscalizar o uso das novas tecnologias, como foi o caso do uso indiscriminado e indisciplinado dos fertilizantes (Kageyama; Graziano da Silva, 1987). Além disto, essas transformações, da forma como foram concebidas, acabaram determinando a ampliação exponencial do proletariado rural, em que a terra deixa de ser espaço exclusivo de produção e torna-se um ativo financeiro que, em determinados momentos, acaba entrando na espiral valorativa da especulação.

Muller (1982), estudando o processo de industrialização no campo, destaca que esse fenômeno teve como característica a presença do grande capital, ainda que não diretamente ligado à atividade agrícola. Para o autor, a industrialização no campo se caracteriza por uma grande difusão do progresso técnico, elevação e concentração do capital, avanço de estruturas oligopolistas e maior distanciamento entre grandes e pequenos. Isso se consubstanciou num maior enriquecimento da agricultura industrial e empobrecimento da agricultura tradicional. 
Conclui-se, assim, que o padrão de intervenção do Estado, sobretudo nas décadas de 1960 e 1970, moldou o processo de desenvolvimento no setor agrícola. Concentrou-se ainda mais a estrutura agrária e as atividades rurais se transformaram em um complexo de atividades agroindustriais. De um lado, oligopólios de indústria para a agricultura e, de outro, oligopsônios de agroindústrias controladas por grandes capitais, sobretudo estrangeiros, e no meio à atividade agrícola e pequenos e médios produtores como tomadores de preços.

Em muitos ramos ocorreu o que Gonçalves (2005) chama de "financeirização da agricultura", em que o agropecuarista para produzir de forma eficiente depende não somente de terras férteis e de trabalho viril, mas, sobretudo, de dinheiro e crédito para ampliar as compras de máquinas, equipamentos, corretivos, defensivos e sementes geneticamente modificadas. Somente se inserindo nessa nova lógica produtiva é que consegue se reproduzir enquanto produtor.

Todas essas transformações fazem com que na atualidade seja impossível separar o setor agrícola do setor industrial. As tentativas de medir a participação do agronegócio no PIB brasileiro chegaram a cifras superiores a 20\% para os anos de 1990 e 2000 (Silva et al., 2006). Porém, reconhece-se que grande parte dos produtos e serviços contabilizados é produzida na cidade, por exemplo, na indústria de fertilizantes, defensivos e máquinas agrícolas, serviços de despacho aduaneiro, embalagens, transportes diversos, etc. Além disso, muitos desses produtos e serviços são controlados por capitais estrangeiros.

Ao fim e ao cabo, a agricultura acabou cumprindo suas "funções" e apesar de uma participação pequena no PIB (considerando apenas a produção agrícola, as commodities) nos idos dos anos 2010, o setor continua desempenhando algumas funções macroeconômicas importantes para o Brasil, sobretudo a geração de superávit primário. Nessa década, despontam avanços das 
N\&Ns e a agropecuária e a agroindústria não passaram inertes a este processo. Resta saber se o Estado será capaz de ativar adequadamente seus instrumentos para além dos creditícios.

Para fins de comparação, lembra-se que a revolução verde ocorrida no Brasil nas décadas finais do século $\mathrm{XX}$, havia ocorrido antes nos países centrais. A diferença é que naqueles países ao passo que se tecnificava a agricultura, havia um concomitante processo de melhoria das condições materiais de vida daqueles que viviam (ou migravam) para as cidades, sobretudo em termos de saneamento. No Brasil, os resultados para as famílias envolvidas foram desastrosos, no campo e na cidade. 0 celeiro do mundo produziu cenários avançados de miséria. Dessa forma, percebe-se o quão desastrosas são as políticas pautadas no anacronismo e nas soluções importadas, e que infelizmente são muito recorrentes no Brasil.

A seguir, apresenta-se a revolução agrícola incolor que já está ocorrendo nos países desenvolvidos com a introdução do novo padrão tecnológico pautado nos avanços das N\&Ns.

\section{A Revolução incolor: nanoagricultura e nanof oods}

De início é importante pontuar o que se caracteriza neste artigo como revolução incolor. Trata-se da utilização da nanotecnologia e da nanociência na produção de alimentos. Por um lado tem-se a intensificação da produção de artifícios tecnológicos aplicados à agricultura e que são produzidos por grandes conglomerados industriais: a) utilização de nanopartículas e nanocápsulas agregadas aos alimentos e bebidas com o objetivo de mudar seu sabor e a textura; b) nanopartículas adicionadas em rações de animais; d) vacinas; e) embalagens inteligentes para controle de temperatura, aumento da durabilidade, f) sementes inteligentes, etc. Assim, mais uma vez, a agricultura aparece fomentando o desenvolvimento industrial (Vijayalakshmi et al., 
2015). Todavia, o auge dessa revolução está na nanofabricação agrícola, a fabricação de alimento molecular, com uma produção sem solo, sem sementes, sem fazendas e fazendeiros (Mukhopadhyay, 2014; Engelman, Aldrovando; Berger Filho, 2013; Chaudhry, Castle; Watkins, 2010). Com essa Revolução incolor, completa-se o ciclo da industrialização da agricultura.

As nanotecnologias têm potencial para impactar muitos aspectos dos sistemas agrícolas e alimentares, pois podem ser aplicadas em toda a cadeia de produção de alimentos, modificando desde a duração do cultivo até o processamento dos alimentos para o consumo final (Meulen et al., 2013). Ainda em meados dos anos 2000, Alves (2005) destacou que já existiam aplicações da nanotecnologia voltadas para a melhoria da fertilidade do solo, produção e melhoria de sementes, fabricação de nanossensores destinados ao monitoramento da saúde animal, remoção de contaminantes do solo via utilização de nanopartículas magnéticas, análises de solo metro a metro com o fim de reduzir o uso intensivo de agrotóxicos.

A evolução das pesquisas na área de nanotecnologia, agricultura e alimentos ao redor do mundo revela a importância que o tema adquiriu nos últimos anos. Uma pesquisa bibliométrica realizada por Mukhopadhyay (2014) mostrou que em um lapso de apenas quatro anos aumentou em mais de 13.000 o número de artigos científicos publicados nessa área. As potenciais aplicações da nanotecnologia na produção e indústria de alimentos são incomensuráveis. Novas pesquisas que estão sendo realizadas incluem a redução de gordura e o teor calórico de alimentos populares como sorvete, o desenvolvimento de alimentos que mudam de cor ou de sabor de acordo com as preferências do consumidor, o aumento do tempo de vida de prateleira de produtos perecíveis, entre outros.

No quadro 01 são sumarizadas as possibilidades que já estão sendo exploradas no âmbito da nanoagricultura e dos nanoalimentos. 
Quadro 01 - Exemplos de pesquisas e possíveis usos de nanotecnologias aplicadas à agricultura.

\begin{tabular}{|c|c|}
\hline Tipo de Produto & Descrição \\
\hline Nanoagroquímicos & $\begin{array}{l}\text { Empresas do setor estão reduzindo para a nanoescala } \\
\text { o tamanho de partículas existentes em insumos quími- } \\
\text { cos utilizados, pesticidas, fungicidas, etc. Além disso, } \\
\text { encapsulam para que abram somente em determinadas } \\
\text { condições, por exemplo: luz solar, calor, condições do } \\
\text { solo, etc. }\end{array}$ \\
\hline $\begin{array}{l}\text { Nanomanipulação gené- } \\
\text { tica de culturas agrícolas } \\
\text { e animais }\end{array}$ & $\begin{array}{l}\text { A nanobiotecnologia oferece novas ferramentas para a } \\
\text { manipulação de genes de plantas ou animais, se utili- } \\
\text { zando da manipulação de nanopartículas, nanofibras } \\
\text { e nanocapsulas, ao invés de usar vetores virais, para } \\
\text { transportar DNA estranho e produtos químicos para } \\
\text { dentro das células. }\end{array}$ \\
\hline $\begin{array}{l}\text { Biologia sintética para } \\
\text { criação de organismos } \\
\text { inteiramente novos. }\end{array}$ & $\begin{array}{l}\text { Biologia sintética é a área que combina Engenharia ge- } \\
\text { nética com nanotecnologia, informática e engenharia. } \\
\text { Estudos já avançam na modificação genética de bacté- } \\
\text { rias, o que era impossível até então. Possivelmente serão } \\
\text { criados, muito em breve, organismos com habilidades de } \\
\text { autorreplicarão. Com isso será possível criar micróbios } \\
\text { sintéticos capazes de produzir nutrientes, vitaminas, aro- } \\
\text { mas e sabores diretamente na planta, potencializando a } \\
\text { diferenciação no comércio de alimentos. }\end{array}$ \\
\hline $\begin{array}{l}\text { Desenvolvimento de } \\
\text { nanossensores para } \\
\text { monitoramento das } \\
\text { plantações }\end{array}$ & $\begin{array}{l}\text { Trata-se do desenvolvimento de mecanismos portáteis } \\
\text { e ágeis de controle de qualidade de alimentos, contro- } \\
\text { le de doenças, melhoria da cultura ou genética animal. } \\
\text { Caminha-se também para o monitoramento remoto } \\
\text { das fazendas, controlando-se a umidade do solo, a tem- } \\
\text { peratura, } \mathrm{PH} \text {, presença de ervas daminhas, etc. }\end{array}$ \\
\hline
\end{tabular}

Fonte: Baseado em Miller e Senjen (2008). 
Assim, aponta-se para o desenvolvimento de um tipo de agricultura completamente nova, em que as cores, as texturas, o tamanho, os cheiros, a quantidade e qualidade de nutrientes (entre eles gordura e açúcar) e os sabores dos diversos tipos de alimentos poderão ser controlados por meio de computadores e de forma remota (Friends of Hearth, 2014; Chene Yada, 2010; Fao e Who, 2010). Percebe-se claramente o poder revolucionário disso, sobretudo quando se considera uma cadeia de produção de alimentos para além das fazendas, incorporando inclusive a manufatura.

As fazendas do futuro próximo poderão reduzir a dependência em relação às intempéries do clima (quantidade de sol e chuva) e solo (qualidade da fertilização). Estas novidades e possibilidades apontariam claramente para uma possível sustentabilidade socioambiental, porém trazem consigo um alto potencial para ampliar a concentração de renda e riqueza em algumas poucas organizações que dominarem essas tecnologias.

De acordo com Miller e Sengen (2008), somente nos Estados Unidos, existiam no ano de 2008 mais de 100 nanoalimentos sendo vendidos em supermercados. Além disto, todos esses alimentos se aproveitam das lacunas regulatórias, mesmo não havendo estudos definitivos acerca de seus efeitos sobre a saúde humana e o ambiente. Por essas razões, entre os especialistas mais críticos em relação ao tema, surge a preocupação com o aumento de produtos não regulamentados e sem rotulagem, em escala exponencial.

Nos países em desenvolvimento as possibilidades dessa revolução invisível são: aniquilação da agricultura familiar; inviabilização das experiências com orgânicos e com a agroecologia, dada a concorrência via custos; possibilidade de domínio completo pelo capital estrangeiro (estratégia de oligopólio pela compra de terras e controle da oferta); novo inchaço urbano, ou resistência fragilizada no campo; intensificação do uso de agrotóxicos por 
aqueles que usam a velha tecnologia a fim de manterem o mínimo de produtividade competitiva.

\section{Enquanto isso, abaixo do equador: uma nanocontradição}

A nanocontradição a que se refere o título desta seção pode ser entendida como um processo em que ao avançarem os usos e aplicações das nanotecnologias para a agricultura, coexista, de um lado, uma precária agricultura de subsistência e, de outro, uma ultramoderna estrutura agrícola/industrial, uma avançada nanoagricultura industrializada, estrangeira ou importada.

Nas duas últimas décadas ficou evidente que o modelo industrial brasileiro fracassou no seu intento de alçar o país ao status de desenvolvido. Todavia, o setor agrícola foi capaz de aumentar a projeção do Brasil no comercio exterior, principalmente quando entraram em cena novos parceiros comerciais como a Zona do Euro e a China. Diante disso, o setor continua sendo subordinado às políticas macroeconômicas, além de servir como campo de fuga dos ativos reais, inclusive para estrangeiros. Dados do INCRA (2011) revelaram que entre os anos 2003 e 2007 aumentou em $22 \%$ e $57 \%$, respectivamente, nas regiões sudeste e nordeste, o percentual de áreas de terras pertencentes a estrangeiros. No ano de 2007, de posse de estrangeiros já eram mais de 5,2 milhões de imóveis ativos cadastrados, ocupando mais de 500 milhões de hectares.

No Brasil, há mais de uma década se faz pesquisa na área de $\mathrm{N} \& \mathrm{~N}$, inclusive apoiadas com financiamento estatal. Aliás, é mister registrar que poucos resultados são encontrados acerca de esforços envidados pelo setor privado brasileiro no âmbito do tema, especialmente quando se conferem os indicadores de patentes. Assim, sob esse prisma é possível dizer que a pesquisa em N\&N no Brasil é uma realidade, porém com pouco investimento público e parco investimento privado. Isso faz com que 
o país esteja completamente vulnerável aos avanços de grandes conglomerados estrangeiros.

Consultando as informações disponíveis no SisNANO (Sistema Nacional de Laboratórios em Nanotecnologia), vinculado ao Ministério de Ciência, Tecnologia, Inovações e Comunicações, verifica-se que atualmente existem 26 laboratórios dedicados às diversas pesquisas na área de N\&N. Entre eles está o Laboratório Nacional de Nanotecnologia Aplicada ao Agronegócio, único diretamente ligado à nanoagricultura, no qual é possível encontrar linhas de pesquisa que abarcam as seguintes áreas: desenvolvimento de sensores e biossensores; fabricação de novos materiais de fonte renovável; membranas de biopolímeros e revestimentos poliméricos comestíveis para preservação de alimentos; estudos nanotoxicológicos e de impactos na saúde e meio ambiente.

A produção científica ligada ao trabalho da equipe de aproximadamente 20 pesquisadores é bastante vasta, e tem servido de referência para inúmeros trabalhos ao redor do mundo, haja vista a quantidade de citações verificadas nas plataformas de aferição (notadamente Web of Science e Scopus). Todavia, os resultados pragmáticos, consubstanciados em produtos e processos disponíveis, ainda parecem muito incipientes, já que não se observam nos números de patentes, bem como nas políticas públicas, os resultados alcançados por essas pesquisas.

A questão é que no aparato decisório brasileiro prevalece uma visão monocrática de agricultura, qual seja, aquela ligada ao desenvolvimento do grande agronegócio, capaz de gerar superávit de divisas. Ainda paira no status quo do conhecimento científico, que muitas vezes dominam algumas agendas políticas, uma total desinformação acerca do que seria produção de alimentos e produção de commodities. Existe, portanto, um conflito ideológico em torno do tema: alimentação da fome versus alimentação da balança comercial. Mais uma vez, na era das nanotecnologias, a 
agricultura possui uma função econômica deliberada, que é produzir superávits comerciais.

Ao focar excessivamente no lado econômico, olvida-se que a agricultura brasileira é o berço de famílias que deixam de inchar os centros urbanos e aumentar seus bolsões de pobreza. Todavia, caso se queira manter o foco no econômico, cabe lembrar que a agricultura familiar é a atividade com maior participação na produção de alimentos. Essa também é importante do ponto de vista macroeconômico, pois impacta diretamente na inflação, aliás, no Brasil é corriqueiro o fenômeno da agroinflação.

Apesar daquilo que imaginam os outsiders teóricos, o setor agrícola brasileiro é uma amálgama complexa, seja pela diferença entre o perfil dos proprietários de terra, seja pelas disparidades de potencial produtivo, seja pelos mecanismos de financiamento, de apoio, de assistência técnica e extensão rural diferenciados. Talvez isso justifique a existência, ao longo dos anos 2000 e início dos anos 2010, de dois ministérios dedicados a pensar as políticas para o meio rural.

Por isso, é importante analisar a agricultura enquanto um processo de reprodução social. A permanência de milhares de famílias no campo, sustentando-se com o fruto de sua produção, contribui com a produção de mais de $70 \%$ dos alimentos que chegam às mesas. De acordo com o Censo Agropecuário de 2006 elaborado pelo Instituto Brasileiro de Geografia e Estatísticas, eram mais de quatro milhões de propriedades empregando sete de cada dez pessoas ocupadas no setor agropecuário. Como destacaram Lowder, Skoat e Singh (2014), a segurança alimentar dos países em desenvolvimento, tal qual o Brasil, é garantida por essa agricultura familiar, que abastece os mercados com produtos tradicionais (mandioca, feijão, arroz, carne suína, aves, peixe), e que apresenta uma relação mais harmônica com a biodiversidade e os recursos naturais, além de manter preservada a cultura local. 
Assim, não parece existir um setor de N\&N para a pequena produção, o que existe é uma indústria de nanotecnologia para a agricultura que estará concentrada nas mãos de eternos oligopólios. O Brasil segue a tendência do que vem ocorrendo em todo o mundo, onde as nanotecnologias estão sob o controle dos agricultores de grande escala, como já vem ocorrendo em países como os Estados Unidos e a Austrália; haja vista a atual concentração de terras. A tendência nos países ricos, portanto, como destacam Myhr e Myskja (2013), é a substituição de "fazendas familiares" por "fazendas corporativas". Nesse contexto, os autores chamam a atenção para a necessidade de desenvolvimento de aplicações nanotecnológicas para a agricultura praticada por agricultores de pequena escala, principalmente dos países em desenvolvimento.

Cabe lembrar que a revolução agrícola brasileira foi promovida pelo Estado na expectativa de solucionar os problemas da agricultura e fomentar o avanço industrial. Porém, poucos foram aqueles que conseguiram vislumbrar os problemas resultantes daquele processo como, por exemplo, a quantidade de trabalhadores que seriam expulsos do campo ocasionando o inchaço urbano, a degradação ambiental e os alimentos impregnados de agrotóxicos que ainda comprometem a saúde humana.

Poucas décadas depois daqueles percalços com profundos reflexos nos tempos atuais, emerge esse novo padrão tecnológico para produção de commodities e/ou de substitutos artificiais que podem comprometer a sustentabilidade de países que dependem destes bens, tal qual o Brasil. É o caso dos estudos em nanopartículas para modificar a borracha, tornando-a muito mais resistente, e das pesquisas na área de fibras artificiais manipuladas na nanoescala que emulam perfeitamente as propriedades do algodão.

Para entender a complexidade dessas relações, é fundamental que novas perspectivas teóricas sejam utilizadas. Por exemplo, nos estudos sobre o desenvolvimento das nanotecnologias 
aplicadas à agricultura parece imprescindível utilizar a perspectiva do Treadmill of production (rotinas ou moinhos da produção). Nessa interpretação, baseadas nos trabalhos de Allan Schnaiberg e Kenneth Gould (Gould, 2015; Schnaiberg, 2000), a nanotecnologia pode viabilizar a junção entre as rotinas relativas aos químicos e à genética culminando no aumento da dependência dos agricultores. Nesse caso, o moinho de produção estaria criando novas formas de dependência tecnológica que, de acordo com Martins (2011), amplia também os riscos financeiros e ambientais das atividades agrícolas.

Todas essas transformações requerem que o nível de reflexão e intervenção seja maior que o atual. 0 Estado tem papel fundamental, seja no financiamento de pesquisas, seja acompanhando com lisura o desenvolvimento dos processos de produção e apropriação dos resultados de pesquisa, isto é, fomentando a criação de um aparato institucional capaz de lidar com os desafios provenientes de revoluções científicas. Na próxima seção algumas possibilidades são rascunhadas.

\section{U ma possível agenda de política}

Antes de se rascunhar uma possível agenda de políticas públicas, é fundamental dizer que o que é recorrente acerca da discussão em tela são as incertezas. Ao mesmo tempo em que se pode aprofundar a disparidade no meio rural também existe a possibilidade de se avançar no desenvolvimento de uma agricultura mais sustentável. Para tanto, é fundamental que se evite tanto a tecnofobia quanto a tecnofilia, e que seja possível a prática do princípio da responsabilidade nos termos enunciados por Jonas (2006), em que a ética e o reconhecimento da incerteza sejam um protocolo na aventura científica.

Os desafios para essa agenda de política e para um avanço mais harmônico das N\&Ns revisitam antigos problemas, entre eles: as 
dificuldades de aproximação dos interesses públicos e privados; a quase inexistente colaboração entre países desenvolvidos e em desenvolvimento no campo do bem-estar; além da controvérsia em torno do grau de regulação, que de um lado permita a livre iniciativa, mas que de outro seja capaz de proteger os interesses coletivos.

A construção das agendas pode levar em conta o seguinte conjunto de questões de trabalho: Qual é o papel do Estado no financiamento das pesquisas envolvendo nanotecnologia e agricultura no Brasil? Se o país não entrar nesse campo, existem possibilidades para além das nanotecnologias agrícolas? Existe alguma função da agricultura tradicional no contexto do paradigma de produção molecular? A sociedade está suficientemente politizada para entender e promover o debate em sua completude? Existe algum componente retrógrado ao se pensar criticamente nesse processo de "desenvolvimento" agrícola via nanotecnologias? A nanociência brasileira não estaria indo de encontro com o tema? 0 Brasil ainda deseja competir internacionalmente exportando alimentos?

Atualmente, no Brasil, os estudos da nanotecnologia estão concentrados em poucas áreas do conhecimento e a interdisciplinaridade necessária para o entendimento do processo é ainda muito escassa (Santos Junior, 2013). A concentração disciplinar se contrapõe ao quesito de interdisciplinaridade que muitos pesquisadores demandam para a área de N\&N. Essa falta de interação entre as diversas áreas do conhecimento promove uma fragilidade significativa na política, ao deixar de promover de forma substancial os estudos críticos acerca do potencial toxicológico, dos impasses éticos, das perspectivas econômicas e sociais a partir do uso e disseminação das nanotecnologias.

No Brasil, é recursiva a visão imediatista e parcial de progresso, que não conseguiu enxergar para além dos resultados "curto-prazistas" em termos de crescimento do produto nacional, e 
fortemente pautada num projeto político de consolidação do setor industrial e da capacidade inovativa. Além disso, sobretudo por ter sido consubstanciada em um período de forte centralização organizativa do governo federal brasileiro, muitas políticas públicas ficaram restritas a alguns grupos de interesse (algumas universidades, poucos setores empresariais, poucas regiões, etc.), inclusive negligenciando a participação da sociedade civil nacional (Santos Junior, 2013).

A formulação da agenda política precisa considerar também que o desenvolvimento tem mais a ver com segurança alimentar e menos com balança comercial agrícola. Além disso, as políticas para agricultura familiar e manutenção do jovem no campo devem ser consideradas e aparecer Políticas de Estado, capazes de promover saúde, educação, lazer, entretenimento aos povos do campo (Santos Junior; Rangel, 2015). A sustentabilidade está mais no uso adequado dos recursos e menos na quantidade produzida.

Assim, no intuito de se construir uma agenda pública para os debates e as ações na área de N\&N aplicadas à agricultura, os stakeholders precisam ter em mente as seguintes perspectivas:

A) Soberania e segurança alimentar

Uma política nacional para a nanoagricultura deve envolver os aspectos da soberania e segurança alimentar. Como visto, parte da agricultura brasileira (a familiar) é capaz de produzir 70\% dos alimentos que chegam às mesas dos brasileiros; outra parte consegue produzir inúmeras commodities que são exportadas e que fortalece o caixa das reservas internacionais.

Assim, não há como dissociar crescimento da produtividade da manutenção da qualidade dos alimentos. Interessante notar que ao redor de todo o mundo cada vez mais se valorizam as iniciativas envolvendo formas mais sustentáveis e saudáveis de produção. Inclusive, no Brasil, no ano de 2015, a temática da Con- 
ferência Nacional de Assistência Técnica e Extensão Rural foi a agroecologia.

O desafio, portanto, é fomentar os campos de pesquisa e as bases de dados sobre possíveis formas de produção limpa, justa, solidária e sustentável na agricultora, capazes de conviver harmonicamente com realidades tecnológicas de alto impacto sem, no entanto, deixar de alimentar adequadamente cada cidadão do país.

\section{B) Controle de mudas e sementes}

As nanotecnologias têm sido aplicadas de forma extensiva no desenvolvimento de sementes inteligentes, muitas vezes com forte comunicação e interdependência com defensivos agrícolas. Todavia, a partir do olhar de diversos especialistas ao longo dos últimos anos, foram apoiadas diversas iniciativas de salvaguarda de sementes crioulas, que já passaram por um processo de seleção natural ao longo de décadas de cultivo.

As experiências de criação de bancos comunitários de sementes é uma atividade que pode continuar sendo incentivada, na medida em que evita o domínio de toda a cadeia produtiva. Pelwing, Frank e Barros (2008) lembram que a salvaguarda dessas sementes é uma forma de se manter a variabilidade e biodiversidade das plantas cultivadas e do conhecimento associado.

Desse modo, ao se fomentar os bancos de mudas e sementes torna-se mais pacífica a coexistência entre a alta tecnologia e a produção tradição, já que o produtor tradicional reduz sua dependência e vulnerabilidade em relação a este tipo de matéria-prima tão cara à agricultura tradicional. 


\section{C) Análises de toxicidade}

No Brasil, diferentemente do que ocorre em muitos países desenvolvidos, existe um amplo desconhecimento por parte da sociedade civil (inclusive dos grupos organizados) acerca do que é N\&N e quais são suas possíveis implicações socioambientais ${ }^{5}$. Isso porque, assim como algumas partes deste artigo, muito do conteúdo soa como ficção científica, distante da realidade do cidadão médio. Pensar qualquer tecnologia prospectada como sendo ficção é um abissal equívoco, já que a base da atividade humana é a ideia e o planejamento do novo. A visão limitada dificulta uma discussão mais ampla acerca de riscos potenciais, condutas precaucionais, entre outras ações necessárias para o desenvolvimento da atividade. Esse quadro faz com que toxicidade seja a área mais incipiente dentro das iniciativas brasileiras em N\&N.

Mukhopadhyay (2014) lembra que no caso da utilização de nanotecnologias na agricultura os cuidados em termos de toxicidade devem ser redobrados. Isso porque pouco se sabe ainda sobre os destinos, o transporte e o comportamento das nanopartículas no meio ambiente. Devido ao contato direto com o meio ambiente, os experimentos e usos das N\&Ns requerem uma atenção maior que os usos comerciais e industriais. Por estas razões, os estudos sobre o entendimento do comportamento das nanopartículas precisam ser agenda prioritária em qualquer iniciativa.

D) M onopólio de cadeias produtivas

0 monopólio é uma estrutura produtiva repugnante, e isto pode ser dito sem ressalvas já que não se encontram em nenhuma literatura (clássica ou moderna, conservadora ou progressista, socialista ou liberal) argumentos que sejam capazes de defendê-

5 Nesse quadro não se encaixa a Rede Brasileira de Pesquisa em Nanotecnologia, Sociedade e Meio Ambiente que é uma das referências na América Latina de ações que buscam a politização social em torno do tema. 
-la. Assim, quando se verifica que o desenvolvimento tecnológico recente no campo da agropecuária, especialmente aquele referente ao uso de OGMs e N\&N, tem provocado uma intensa concentração do setor, saltam aos olhos os equívocos deste processo. E o aspecto mais complexo é que essa concentração tem se dado desde a posse de terras à comercialização dos produtos.

Uma estratégia nacional para a nanoagricultura deveria trazer como mote a perspectiva da difusão do conhecimento e desenvolvimento de tecnologias capazes de serem reproduzidas por quaisquer tipos de produtores. 0 objetivo é evitar o controle absoluto de tecnologias e insumos, sobretudo daquelas tecnologias produzidas a partir do emprego de diversos recursos públicos.

Nesse encalço, as experiências de produção de conhecimento colaborativo, a estratégia de creative commons, entre outras ações de compartilhamento de ideias e ações efetivas, podem ser incentivadas a todo o momento. Dessa forma, é possível respeitar os anseios da propriedade privada do conhecimento consubstanciado em patentes e direitos de uso, mas sem se prender às suas amarrasse possíveis prejuízos para o coletivo.

\section{E) Recursos H umanos}

Para que se logre um avanço seguro e sustentável no campo das nanotecnologias aplicadas à agricultura e aos alimentos é fundamental que os recursos humanos sejam bem treinados para experimentar, inovar, avaliar, interpretar e assimilar de forma crítica e baseada no princípio da precaução as ferramentas e técnicas (Mukhodadhay, 2014). Como observou Mukhopadhyay (2014), nos países desenvolvidos, as relações aqui esboçadas e os efeitos de nanomateriais sobre as cadeias alimentares, os resíduos agrícolas e os potenciais riscos associados também não recebem atenção suficiente nos cursos de formação em nanotecnologia. 
Atualmente, no Brasil, existe apenas um curso de graduação dedicado ao ensino de N\&N. Além disso, nanotecnologia é ensinada nos cursos tradicionais de física, química em algumas instituições tradicionais, tanto na graduação quanto na pós-graduação. Poucas são as experiências de cursos que envolvem as engenharias, as ciências humanas e os outros campos científicos de forma interativa. Os programas de ensino da nanotecnologia nessas instituições pouco exploram junto aos alunos as questões críticas, sobretudo quando o tema em debate é agricultura e os alimentos. Por essas razões, existe uma demanda premente no desenvolvimento de recursos humanos e entendimentos sobre a complexidade da relação envolvendo produção agrícola, produção de alimentos, consumo e segurança alimentar em um contexto de inserção ativa das nanotecnologias.

O desenvolvimento dos recursos é importante não somente para se qualificar e ampliar as ações internas, mas também para politizar a sociedade em relação a esta nova onda de desenvolvimento com potencial de transformação paradigmática. Aliás, neste artigo se reconhece que o novo paradigma já se encontra em curso e, portanto, já existe um atraso em termos de capacitação.

F) Ética na prática produtiva e na pesquisa científica Todas as ações anteriores podem ser substituídas pela prevalência da ética nas atividades produtivas e científicas na área de N\&N. Com reponsabilidade, com olhar crítico, com a perspectiva de respeito ao meio ambiente e ao ser humano é possível prescindir de todo e qualquer aparato regulatório. Todavia, ao contrário do que se afirmou em relação às tecnologias revolucionárias, essa ética ainda parece ser uma ficção.

\section{G) Regulação}

Na ausência da ética, o Estado precisa lançar mão de um recurso tão caro às democracias, a regulação. É preciso dizer que a regu- 
lação somente existe porque predominam falhas nos mecanismos de auto-organização social.

Na esteira de uma nova onda liberalizante ensejada sempre no seio de alguma grande crise, nos últimos três ou quatro anos observa-se um crescimento, no Brasil, de uma simpatia deliberada pela Escola Austríaca da Economia, que tem Ludwig Von Mises como seu maior expoente, e que prega um ideal de liberdade que se levada a cabo prescindiria de qualquer instituição de controle. A disseminação dessas ideias tem promovido o surgimento de grupos que comungam de uma espécie de devoção radical, compostos, sobretudo, por jovens afetos às novas tecnologias, aos princípios da liberdade econômica no seu sentido mais profundo, e que tendem a ser contra toda e qualquer forma de atuação do Estado. Nesse contexto, o ordenamento jurídico apareceria apenas como um instituto com a única função de permitir o livre funcionamento do mercado.

A proliferação de Blogs, colunas de jornais e institutos de pesquisa e de disseminação desses ideais, inclusive financiados por instituições formais de representação de esferas específicas da sociedade empresarial, evidencia que o argumento da livre iniciativa e livre concorrência não se trata apenas de uma saída semântica e/ou jurídica para justificar a permanência do negócio diante do vácuo institucional. Ao contrário, parece algo que se liga mais diretamente a uma perspectiva teórico-ideológica que vê nas instituições do Estado uma grande barreira para o desenvolvimento da economia de mercado.

No entanto, utilizando-se dos próprios argumentos liberais, toda e qualquer iniciativa pode ser livre, desde que seja capaz de garantir que suas ações não interfiram no bem-estar alheio. Por isso, o marco regulatório, "deve abarcar uma gama variada de riscos ainda sem uma devida fundamentação científica, mas com a produção já chegando ao mercado consumidor" (Engelmann, Aldrovandi e Berger Filho, 2013, p. 118). Veja-se que não 
parece nada radical, ou mesmo injustas, propostas dessa natureza. Trata-se de uma perspectiva simples, em que se invocaria o princípio da precaução quando faltarem informações suficientes sobre caminhos e descaminhos das novas tecnologias.

\section{Considerações finais}

Ao longo deste artigo ficou clara a aproximação dos eventos que ocorreram entre os anos 1960 e 1970 e o processo em curso envolvendo o desenvolvimento das nanotecnologias. Se a negligência naquele caso produziu efeitos nefastos para o meio ambiente e para a organização social, sua repetição no caso atual tende a promover rupturas profundas e irreparáveis para a soberania do país.

A estratégia de desenvolvimento em nanociência e nanotecnologia precisa ser capaz de pensar todos os elos da cadeia de valor da agricultura, buscando prever seus possíveis impactos. Assim, é possível praticar um desenvolvimento tecnológico ambientalmente responsável e socialmente justo. Para tanto, é impossível prescindir do desenvolvimento de mecanismos e instâncias de governança e regulação que incluam todas as partes interessadas. Ao menos deve haver a previsão dos instrumentos necessários para fazer com que haja o mínimo de autonomia estatal no que se refere ao gerenciamento de riscos, conflitos e incertezas.

As novidades nanotecnológicas requerem um aparato de regulação substancialmente novo, já que trabalham com questões inexistentes até o momento. Por essas razões, argumentos a favor da desregulamentação ou aproveitamento do aparato existente tendem a ilegitimidade.

Em tempos de crise de alimentos e novo paradigma produtivo, parece que agricultura, nanotecnologia e política industrial são 
mais questões de filosofia, ética e economia política e menos de macroeconomia. Ainda nesses tempos incertos parece ser inequívoca a relevância das ciências humanas e sociais no planejamento de um país em desenvolvimento, onde as inúmeras tentativas de se emparelhar com os desenvolvidos promoveram mais disparidades que coesão. Sem essa contribuição, corre-se o risco da tecnologia do futuro coexistir com uma sociedade sem memória, sem crítica, sem história. E não há nada mais retrógrado do que viver nessa possível conjuntura.

\section{Ref erências}

ALVES, O. L. Nanotecnologia e Desenvolvimento. Campinas, SP: LQES NEWS, 2005 (Artigo de Divulgação).

BRASIL. Instituto Brasileiro de Geografia e Estatística. Censo Agropecuário: Agricultura Familiar: Primeiros Resultados 2006. Rio de Janeiro, Instituto Brasileiro de Geografia e Estatística - IBGE.

CHAUDHRY, Q.; CASTLE, L.; WATKINS, R. Nanotechnologies in food. Royal society of Chemistry, RSC Nanotechnology and a nanoscience, n. 14, 2010.

CHEN, H.; YADA, R. Nanotechnologies in agriculture: new tools for sustainable development. TrendsFoodSciTechnol. 2011;22:585-594.

DELGADO, G. A questão agrária no Brasil, 1950-2003. In: JACCOUD, L. (org.). Questão social e políticas sociais no Brasil Contemporâneo. Brasília: IPEA, 2005 (p. 51-90).

ENGELMANN, W.; ALDROVANDI, A.; BERGER FILHO, A. G. Perspectivas para a regulação das nanotecnologias aplicadas a alimentos e biocombustíveis. Vigilância Sanitária em Debate, Rio de Janeiro, v. 1, n. 4, p. 115-127, 2013.

FAO \& WHO. FAO/WHO Expert meeting on the application of nanotechnologies in the food and agriculture. Sectors: potential food safety implications, 2010. Disponível em: http://www.fao.org/docrep/012/i1434e/ i1434e00.pdf, acesso em: 01 de ago.2016.

FRIENDS OF HEARTH. Tiny Ingredientes, Big Risks: Nanomaterial rapidly entering food and farming. May, 2014. Disponível em: http://www.foe.org/ news/news-releases/2014-05-new-report-tiny-ingredients-big-risks, acesso em: 20 ago.2016. 
GONÇALVES NETO, W. Estado e agricultura no Brasil: política agrícola e modernização econômica brasileira 196-1980. São Paulo: hucitec, 1997.

GONÇALVES, J.S. Agricultura sob a égide do capital financeiro: passo rumo ao aprofundamento do desenvolvimento dos agronegócios. Informações Econômicas, São Paulo, v. 35, n. 4, p. 7-36, abr. 2005.

GOULD, K. Slowing the Nanotechnology Treadmill: Impact Science vs. Production Science for Sustainable Technological Development. Environmental Sociology. 1:3, 143151.2015.

INCRA. Sistema Nacional de Cadastro Rural (SNCR). Brasília: Divisão de fiscalização e controle de aquisição de terras por estrangeiros, 2011.

JONAS, H. 0 princípio responsabilidade: ensaio de uma ética para a civilização tecnológica. Rio de Janeiro: Contraponto; Ed. PUC-Rio, 2006.

KAGEYAMA, A.; GRAZIANO DA SILVA, J. A dinâmica da agricultura brasileira: do complexo rural aos complexos agroindustriais. Campinas: IE/unicamp, 1987.

LEITE, S. Estado, padrão de desenvolvimento e agricultura: o caso brasileiro. Estudos Sociedade e Agricultura, 13(2), 2005. pp.280-332.

LOWDER, S. K.; SKOET, J.; SINGH, S. What do we really know about the number and distribution of farms and family farms worldwide? Background paper for The State of Food and Agriculture 2014. ESA Working Paper No. 14-02. Rome: FAO, 2014.

MARTINS, P. R. Nanotecnologia como a "base de uma nova revolução verde": impactos e consequências para o desenvolvimento rural. ANAIS.... XXVIII CONGRESSO INTERNACIONAL DA ALAS. 6 a 11 de setembro de 2011, UFPE, Recife-PE GT05- Desenvolvimento rural, globalização e crise, 2015.

MEULEN, B. V. D.; et al. Nano Foods: Principles-Based Responsive Regulation: EFFoST. San Diego: Elsevier, 2014.

MILLER, G.; SENJEN, R. Out of the Laboratory and on To Our Plates: Nanotechnology in Food \& Agriculture, Friends of the Earth Australia, Europe and US. Melbourne, 2008.

MUKHOPADHYAY, S. S. Nanotechnology in agriculture: prospects and constraints. NanotechnolSciAppl. 7: 63-71, 2014.

MÜLLER, G. Agricultura e industrializaçãodocampo no Brasil. Revista de EconomiaPolítica, 2 (1), 1982.

MYHR, A.I. and MYSKJA, B.K. Nanotechnology in Agriculture. Encyclopedia of Food and Agricultural Ethics. Springer-Verlag Berlin Heidelberg, 
2013. Disponível em: http://www.springerreference.com/index/chapterdbid/307735, acesso em 01 de jul.2016.

PELWING, A. B.; FRANK, L. B. and BARROS, I. I. B. de. Sementes crioulas: o estado da arte no Rio Grande do Sul. Rev. Econ. Sociol. Rural [online]. 2008, vol.46, n.2, pp.391-420.

REGIS, E. Nano. Rio de Janeiro: Rocco, 1997.

SANTOS JUNIOR, J. L. Ciência do futuro e futuro da ciência: redes e políticas de nanociência e nanotecnologia no Brasil. Rio de Janeiro: Eduerj, 2013.

SANTOS JUNIOR, J.L. ; CHAIN, C. P. . Nanotecnologia e agricultura no Brasil: Estado da arte e a arte de Estado. In: XIII Encontro da Associação Nacional de Pós Graduação e Pesquisa em Planejamento Urbano e Regional, 2009, Florianópolis/SC. Anais do XIII ENAnpur. Universidade Federal de Santa Catarina., 2009.

SANTOS JUNIOR; J. L. dos; RANGEL, S. S. A. Desafios da sucessão na agricultura familiar: os jovens e os direitos a uma vida justa no campo. In: SANTOS JUNIOR, J. L. dos; AFONSO, A. S. Desafios para o desenvolvimento capixaba: uma perspectiva transdisciplinar. Curitiba: CRV, 2016.

SCHNAIBERG, A. The Treadmill of production and environmental State. Chicago, Illinois, U.S.A. April, 2000.

SCHUMPETER, A Joseph. Teoria do desenvolvimento econômico. São Paulo: Abril Cultural, 1982.

SILVA, M.V. et al. A participação do agronegócio no PIB brasileiro: controvérsias conceituais e propostas metodológicas. Anais do Congresso Brasileiro de Economia e Sociologia Rural. Brasília, SOBER, 2006.

VIJAYALAKSHMI et al., Biosci., Biotech. Res. Asia, Vol. 12(1), 327-331 (2015).

ZUBAREV, E. R. Nanoparticle synthesis: any way you want it. Nat Nanotechnol. 2013;8:396-397.

Recebido em 21/05/2016

Aprovado em 27/07/2016 
